\section{In the News}

In last month's issue I encouraged you to volunteer to serve on one of ACRL's many committees. This issue shows the results of those volunteer efforts in the summary of activities provided in the ACRL 1991-92 Annual Report.

ACRL members accomplished much this past year including: they held their 6th National Conference, the most highly rated one ever; offered 20 programs, a 3-day preconference, and numerous opportunities for discussion and networking at the ALA Annual Conference; prepared and published three new books; improved the image of librarians presented in many career guidance packages; developed new guidelines to aid you in your workplace; presented nine awards to academic librarians and libraries; and offered Choice reviews online.

I encourage you to spend some time with the Annual Report reviewing what the combined efforts of volunteers across the country can accomplish.

This issue also examines the impact of technology on academic reference services. Ann Bristow shares her experiences providing ref- erence service using electronic mail at Indiana University and offers suggestions for setting up such a service. Adeane Bregman and Barbara Mento suggest that the proper point of contact between a reference librarian and a patron is not always the reference desk.

Reports from two conferences are also included in this issue. Barbara Ford shares with us her experiences attending the International Federation of Library Associations and Institutions (IFLA) conference in New Delhi, India, and Sheila Delacroix offers us a look at the Black Caucus of the ALA (BCALA) conference in Columbus, Ohio. In "Racial and Ethnic Diversity" Susana Hinojosa provides information on three conferences being held by other professional organizations.

Also in this issue, Carol Henderson of ALA's Washington Office gives us the latest funding levels for selected library and higher education programs for FY 1993.

- Mary Ellen K. Davis Editor \& Publisher U38398@uicvm.uic.edu

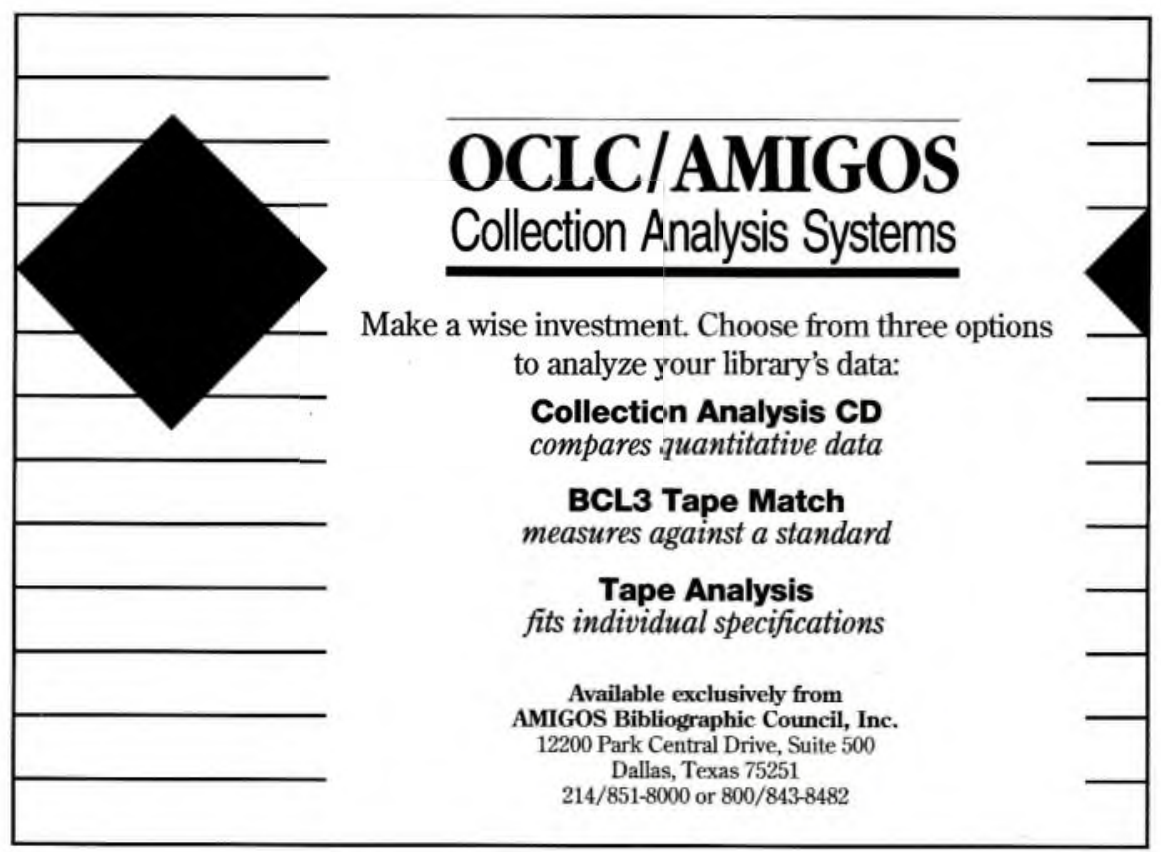

